\title{
Psychological Effects of Boko Haram Insurgencies in Some Liberated Communities across Yobe State, Nigeria
}

\author{
Zara Musa $^{1^{*}}$ Babagana Muhammad Gaji ${ }^{2} \quad$ Umar Baba Sale ${ }^{1}$ \\ 1.Department of Sociology, Faculty of Social and Management Sciences, Yobe State University, Damaturu. \\ Yobe State, Nigeria \\ 2.Centre for Research Innovation and Linkages, Yobe State University, Damaturu. Yobe State, Nigeria
}

\begin{abstract}
Millions of people have been exposed to Boko Haram insurgencies in the last decade, systematic studies on the mental health consequences in affected communities are still rare. This study investigates the psychological effects of the insurgency across several affected communities within Yobe state, Nigeria. Participants from five (5) war-affected local governments in Yobe state were recruited through a random-walk technique. In each of these regions, 3 affected localities were randomly selected, resulting in a selection of 15 localities across all 5 local governments. In each locality, 3 streets were randomly identified. Every fourth household was selected until a maximum of 5 interviews for one street were completed. The history of potentially traumatic experiences were assessed using a specifically amended version of the Life Stressor Checklist. The study shows a strong positive correlation between exposures to traumatic events as a result of the insurgency with the development of psychological stress. Over one third $(36.01 \%)$ of respondents met symptom criteria for post-traumatic stress disorder (PTSD) and close to half $(47.90 \%)$ of the respondents met symptom criteria for depression. Men were more exposed to trauma events, however women developed higher symptoms of psychological stress compared to men. Conclusively, the study provide evidence of mental health distress among populations exposed to Boko Haram insurgencies in Yobe state, Nigeria.
\end{abstract}

Keywords: Boko Haram; Communities; Psychological Stress and Yobe State.

DOI: $10.7176 / \mathrm{DCS} / 11-7-04$

Publication date:July $31^{\text {st }} 2021$

\subsection{Introduction}

Insurgency is a rebellion against authority, when those taking part in the rebellion are not recognized as belligerents (lawful combatants). An insurgency can be fought via counter-insurgency warfare, and may also be opposed by measures to protect the population, and by political and economic actions of various kinds aimed at undermining the insurgents' claims against the incumbent regime (Šmihula, 2013).

Boko Haram, a Jihadist group founded in 2002 by Mohammad Yusuf is involved in series of rebellion attacks particularly in the far north eastern states. Its increasing radicalization led to the suppression operation by the Nigerian military forces and the summary execution of its leader Mohammed Yusuf in July 2009. Its unexpected resurgence, following a mass prison break in September 2010 in Bauchi, was accompanied by increasingly sophisticated attacks, initially against soft targets, but progressing in 2011 to include suicide bombings of police buildings and the United Nations office in Abuja. The government's establishment of a state of emergency at the beginning of 2012, extended in the following year to cover the entire northeast of Nigeria, led to an increase in both security force abuses and militant attacks (David, 2019).

Of the 2.3 million people displaced by the conflict since May 2013, at least 250,000 have left Nigeria and fled into Cameroon, Chad or Niger. Boko Haram killed over 6,600 in 2014.The group have carried out mass abductions including the kidnapping of 276 schoolgirls from Chibok in April 2014. Corruption in the security services and human rights abuses committed by them have hampered efforts to counter the unrest (Glenn, 2014).

In mid-2014, the militants gained control of swaths of territory in and around their home state of Borno, estimated at 50,000 square kilometers in January 2015, but did not capture the state capital, Maiduguri, where the group was originally based. On 7 March 2015, Boko Haram's leader Abubakar Shekau pledged allegiance to the Islamic State of Iraq and the Levant, rebranding as Islamic State in West Africa. In September 2015, the Director of Information at the Defense Headquarters of Nigeria announced that all Boko Haram camps had been destroyed but attacks from the group continue. In 2019, president of Nigeria, claimed that Boko Haram was "technically defeated". However, attacks by Boko Haram have escalated and it still poses a major threat as of today

\subsection{Materials and Methods}

\subsection{Study Area}

Yobe is a state located in northeastern Nigeria. A mainly agricultural state, it was created on August 27, 1991. Yobe State was carved out of Borno State. The capital of Yobe State is Damaturu. Boko Haram's attacks in Yobe include those in Damaturu in November 2011, December 2011 and June 2012, Potiskum in December 2012, 
November 2014 and July 2015, Mamudo in July 2013, Buni Yadi in February and May 2014 and Dapchi in 2018 , Geidam in 2020 and 2021.

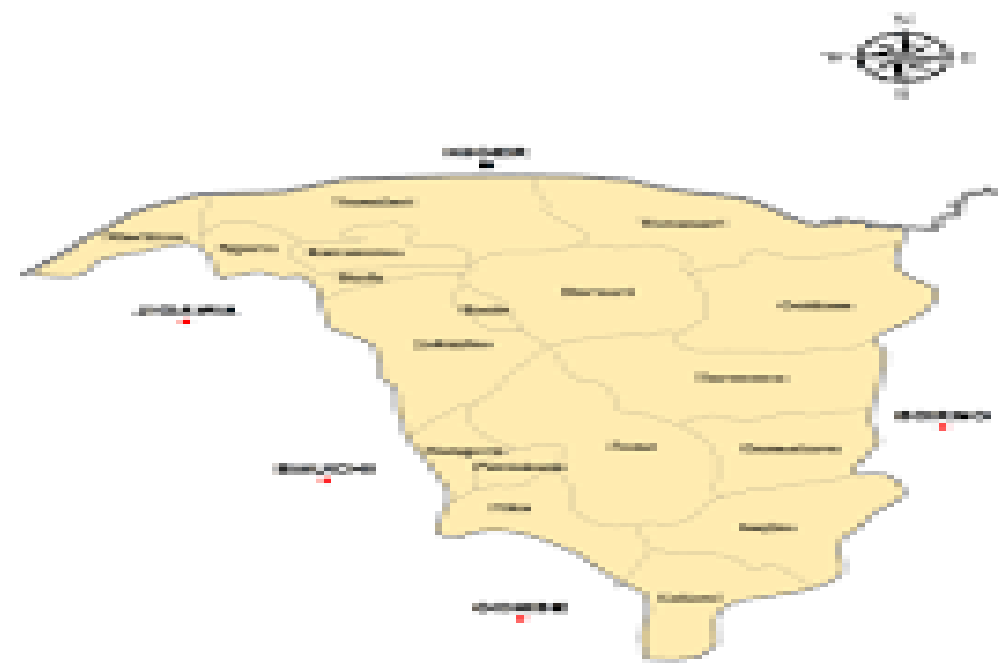

Figure 1: map of Yobe State, Nigeria

\subsection{Sampling Techniques and Participants}

The study was conducted as a multicenter survey in five different local governments (Damaturu, Potiskum, Gujba, Dapchi and Geidam). In each local governments, interviewees were selected using a multistage probabilistic sampling frame and random-walk technique. Firstly, all administrative regions that had been directly exposed to war activities, including bombing, artillery shelling, or combat fire were identified.

In each of these regions, 3 affected localities was randomly selected, resulting in a selection of 15 localities across all 5 local governments. In each locality, 3 streets were randomly identified. Every fourth household was selected until a maximum of 5 interviews for one street were completed. If there were several households in the same building, households were chosen randomly, but no more than 2 participants were interviewed per building. Advance notifications informing residents of the study purpose and planned visit were communicated through their local administrators.

\subsection{Inclusion Criteria}

The interview was conducted with the eligible adult member who are domiciled within the territory of the affected communities; age between 18 and 65 years; experienced at least 1 war-related potentially traumatic event; no severe learning difficulty; and no mental impairment owing to a brain injury or other organic cause.

\subsection{Exclusion Criteria}

People who had not been in the local governments. During wartime and those who had experienced only secondary trauma (e.g, hearing about the disappearance or murder of a family member, or friend) were not included. Researchers made up to 3 attempts at different times of the day and on different days of the week to interview eligible participants, after which a replacement participant from another household was identified following the same sampling procedure.

\subsection{Procedures and Measures}

All interviews were conducted face-to-face. Participant's age, sex, marital status, educational level, and employment status were obtained on a brief structured questionnaire. The history of potentially traumatic experiences were assessed using a specifically amended version of the Life Stressor Checklist. This questionnaire help assesses whether a participant had experienced any potentially traumatic events before, during, and after the war. All interviewers were trained in the assessments used in the survey. An agreement on an item was reached when all interviewers gave it the same answer. Written informed consent was obtained from all participants before the interview.

\subsection{Statistical Analysis}

Descriptive statistics was used to report experiences and characteristics of the samples in each local government. The prevalence rates of mental disorders was calculated as percentages of participants with a positive diagnosis. Multivariate logistic regression was used to analyze the association of demographic, displacement and trauma exposure variables on the outcomes of PTSD and depression. Prevalence rates were reported. 


\subsection{Results and Discussion}

\subsection{Results}

Table 1 shows the sampling profile of the study, a total of two hundred and sixty one (261) individual were involved, thirty six (36) were none consenting to the research, twelve (12) individuals failed to complete the interview while two hundred and thirteen (213) respondents completed the study fully.

Table 1: Sampling profile of the respondents

\begin{tabular}{ll}
\hline Category & Total Number \\
\hline Non-consenting individuals & 36 \\
Incomplete individual interviews & 12 \\
Completed individual interview & 213 \\
Total & 261 \\
\hline
\end{tabular}

The socio-demographic characteristics of the participants was shown in table two, the mean age of the respondents was found to be twenty eight (28) years, with more Muslims and men in terms of religion and gender respectively. More than $50 \%$ of the respondents were married in terms of marital status, while majority of them attended only primary school and have never experienced any displacement prior to the insurgency.

Table 2: Socio-demographic characteristics the respondents $(N=261)$

\begin{tabular}{ll}
\hline Characteristics & Number (\%) \\
\hline Number of Men & $152(58.23)$ \\
Number of women & $109(41.77)$ \\
Mean age & 28 years \\
Religion & \\
Muslim & $242(92.72)$ \\
Christian & $19(7.28)$ \\
Marital status & \\
Married & $142(54.40)$ \\
Single & $94(36.00)$ \\
Divorced/separated & $19(7.27)$ \\
Widowed & $06(2.32)$ \\
Education level & \\
Never attended school & $74(28.35)$ \\
Primary school & $93(35.63)$ \\
Secondary school & $59(22.60)$ \\
Post-secondary school & $35(13.40)$ \\
Displacement Characteristics & \\
Never forcibly displaced & $199(76.50)$ \\
Previously displaced as IDP & $13(5.10)$ \\
Currently IDP & $22(8.43)$ \\
Displaced more than once & $27(10.34)$
\end{tabular}

Table 3 presents the participants response to potentially traumatic events according to gender of the respondents. It was found that women were significantly derived of medical care and exposed to rape compared to male. However, males experience severe forced separation from family members, imprisonment, lack of shelter and abduction compared to the females

Table 3: Exposure of the respondents to various traumatic events according to gender $(\mathrm{N}=\mathbf{2 6 1})$

\begin{tabular}{lccc} 
Trauma event & Men $(\mathbf{N}=\mathbf{1 5 3})$ & Women $(\mathbf{N}=\mathbf{1 0 8})$ & Total $(\mathbf{N}=\mathbf{2 6 1})$ \\
\hline Lack of food or water & $87(56.86)$ & $86(79.62)$ & $173(66.28)$ \\
Unnatural death of family & $08(5.22)$ & $12(11.11)$ & $20(7.66)$ \\
Murder of family/friend & $33(21.56)$ & $21(19.44)$ & $54(20.68)$ \\
Sick without medical care* & $37(24.18)$ & $54(50.00)$ & $91(34.86)$ \\
Lack of housing or shelter* & $101(66)$ & $67(62.03)$ & $168(64.36)$ \\
Being close to death & $66(43.13)$ & $45(41.67)$ & $111(42.5)$ \\
Forced separation from family* & $81(52.94)$ & $56(51.85)$ & $137(52.49)$ \\
Serious injury & $34(22.22)$ & $21(19.44)$ & $55(21.07)$ \\
Tortured or beaten & $19(12.41)$ & $32(29.62)$ & $51(19.54)$ \\
Imprisonment* & $12(7.84)$ & $02(1.85)$ & $14(5.36)$ \\
Forced to accept thoughts against will* & $33(21.56)$ & $05(4.62)$ & $38(14.55)$ \\
Being abducted or kidnapped* & $14(9.15)$ & $03(2.77)$ & $17(6.51)$ \\
Rape or sexual abuse* & $08(5.22)$ & $26(24.07)$ & $34(13.02)$ \\
\hline
\end{tabular}

\footnotetext{
* Statistically significant $(\mathrm{P}<0.05)$ difference between men and women
} 
The prevalence rate of symptoms of post-traumatic stress disorder (PTSD) and depression among the study population was shown in table four below. It was shown that women suffers more psychological stress compared to men.

Table 4: Prevalence rate of symptoms of Post-Traumatic Stress Disorder and Depression $(\mathbf{N}=261)$

\begin{tabular}{lll}
\hline & PTSD N (\%) & Depression N (\%) \\
\hline Total & $94(36.01)$ & $125(47.90)$ \\
Men & $36(38.30)$ & $52(41.60)$ \\
Women & $58(61.70)$ & $73(58.40)$ \\
\hline
\end{tabular}

\subsection{Discussion}

Over the last decade, Boko Haram insurgency have claimed tens of thousands of lives and displaces over 3 million according to the Global Terrorism Index. This is the first study to be conducted on mental health in postconflict Yobe state, one of state severely affected by the insurgency.

A total of two hundred and sixty one (261) participants were recruited for the study. One third (36.01\%) of respondents met symptom criteria for PTSD while almost half $(47.90 \%)$ met reported symptom for depression. This is in accordance with the study of Bayard et al (2009) who reported PTSD and depression rates of 36.23\% and $49.99 \%$ amongst of residents of Juba, Southern Sudan (Bayard et al., 2009).

The study revealed high exposure to trauma among the population of affected communities in Yobe, with nearly one third of respondents experiencing seven (7) or more of the thirteen (13) trauma events covered in the questionnaire. Another important finding was the established evidence of continued exposure to traumatic events amongst populations despite claim of security control by the authorities in Nigeria.

Correlation analysis of trauma events with psychological stress reveal significant associations of independent variables with outcomes of PTSD and depression after adjusting for socio-demographic variables. Although men suffered higher exposure to traumatic events, Women are at particularly high risk of poor mental health. This could be due to the psychological consequences of rape, sick without medical care and been tortured. Several studies on mental health of displaced populations reported similar findings (Pham et al., 2004; Vinck et al., 2007 and Johnson and Thompson, 2008).

This is the first study to investigate the association of individual trauma exposure variables with psychological distress among post conflict survivors in Yobe. Evidence on the role of these individual trauma variables has not been previously studied in Yobe despite a decade long conflict. This highlights the negative effect that deprivation of basic goods and services in post-conflict region has upon mental health.

\section{Limitations}

The limitation of this study is the reported concerns over the use of metrics for analyzing specific mental health conditions of war-affected populations in different cultural settings, respondents may over-estimate symptom scores

\section{Conclusion}

The study established the presence of post conflict psychological distress among populations affected with Boko Haram insurgencies across Yobe state, northeast Nigeria. However, further investigation is required to explain gender-differences in the response to traumatic events.

\section{Acknowledgements}

This work was supported by Tertiary Education Trust Fund (Tetfund) Institutional Based Research grant.

\section{References}

Bass J., Bolton P. and Murray L. (2007). Do not forget culture when studying mental health. The Lancet. 370:918-917.

Bayard R., Eliaba Y.D., Olivia L. and Egbert S. (2009). Post-conflict mental health needs: a cross-sectional survey of trauma, depression and associated factors in Juba, Southern Sudan. BMC Psychiatry. 9(7):1-10 doi: 10.1186/1471-244X-9-7.

Bolton P. and Betancourt T.S. (2004). Mental health in postwar Afghanistan. JAMA, 292(5):626-628.

David C. (2019). The Rise of Boko Haram in Nigeria. Combating Terrorism Center. "There is no doubt that the suppression operation of 2009, and the killing of Muhammad Yusuf by Nigerian security forces in July of that year, was a turning point for Boko Haram Retrieved 27 March 2021.

Glenn K. (2014). Boko Haram: Inside the State Department debate over the 'terrorist' label. The Washington Post. Retrieved 3 August 2020.

Johnson H. and Thompson A. (2008). The development and maintenance of post-traumatic stress disorder (PTSD) in civilian adult survivors of war trauma and torture: A review. Clinical Psychology Review. 
28(1):36-47.

Pham P.N., Weinstein H.M. and Longman T. (2004). Trauma and PTSD symptoms in Rwanda: implications for attitudes toward justice and reconciliation. JAMA. 292(5):602-612.

Šmihula D. (2013): The Use of Force in International Relations, Pp. 67, ISBN 978-80-224-1341-1.

Vinck P., Pham P.N., Stover E. and Weinstein H.M. (2007). Exposure to war crimes and implications for peace building in northern Uganda. JAMA. 298(5):543-554. 